Linha D'Água (Online), São Paulo, v. 31, n. 1, p. 171-191, jan.-abril 2018

\title{
DIALOGISMO INTERLOCUTIVO E CONSTRUÇÃO DA AUTORIA EM ARTIGOS CIENTÍFICOS
}

\section{INTERLOCUTORY DIALOGISM AND CONSTRUCTION OF AUTHORSHIP IN SCIENTIFIC PAPERS}

\author{
Fosé Cezinaldo Rocha Bessa* \\ Universidade do Estado do Rio Grande do Norte, Pau dos Ferros, RN, Brasil
}

\begin{abstract}
Resumo: Compreendendo que o interlocutor a quem o dizer é dirigido desempenha papel essencial nas escolhas estilísticas do sujeito que fala/escreve, da conversação cotidiana a um tratado cientifico, examinamos, neste trabalho, a construção da autoria na escrita cientifica, objetivando identificar e analisar formas de dialogismo interlocutivo como marcas de construção da voz autoral do sujeito pesquisador na escrita de artigos cientificos. Os pressupostos teóricos do Cirrulo de Bakhtin acerca da abordagem dialógica da linguagem, em diálogo com trabalhos de estudiosos que discutem a escrita cientifica, constituem nossa ancoragem teórica central. 0 exame dos 10 artigos cientificos coletados em anais de um dos eventos da Associação Brasileira de Linguística, que consitiuem o corpus da investigaccão, foi orientado pelo enfoque interpretativo e pela abordagem qualitativa da pesquisa. A análise dos artigos coletados permitiu identificar uma variedade de marcas que indiciam os intensos diálogos que o produtor trava com seus interlocutores na construção do dizer. A interpretacaço das marcas identificadas indica que o produtor orienta e orquestra o seu dizer no horizonte de reaç̦oes, expectativas, julgamentos e apreciações de seus interlocutores, configurando, assim, uma construção autoral que se rediza de maneira fortemente marcada pela dimensão do dialogismo interlocutivo.
\end{abstract}

Palavras-chave: dialogismo interlocutivo; autoria; artigo cientffico; ABRALLN; Círculo de Bakhtin.

\begin{abstract}
Understanding that the interlocutor to whom one enunciates plays an essential role in the stylistic choices of the subject who speaks / writes, from everyday conversation to a scientific treatise, we examined, in this research, the construction of authorship in scientific writing, aiming to identify and analyze forms of interlocutory dialogism as marks of construction of the authorial voice of the researcher subject in the writing of scientific papers. The theoretical assumptions of the dialogical approach of Bakhtin's language circle, in dialogue with research of scholars discussing scientific writing, constitute our central theoretical anchorage. The examination of the 10 scientific papers collected in annals of one of the events of the Brazilian Association of Linguistics, which constitute the corpus of the investigation, was guided by the interpretative approach and the qualitative approach of the research. The analysis of the collected articles allowed us to identify a variety of marks that indicate the intense dialogues that the witers hold with their interlocutors in the construction of the saying. The interpretation of the identified marks indicates that the writers guides and orchestrates their act of saying in the horizon of reactions, expectations, iudgments and appreciations of their interlocutors, configuring, thus, an authorial construction that takes place in a strongly marked way by the dimension of interlocutory dialogism.
\end{abstract}

Keywords: Interlocutory Dialogism; Authorship; Scientific Paper; ABRALIN; Bakhtin Circle.

* Professor doutor da Universidade do Estado do Rio Grande do Norte - UERN, Campus de Pau dos Ferros, Pau dos Ferros, RN, Brasil; e-mail: cezinaldobessauern@gmail.com 
Linha D'Água (Online), São Paulo, v. 31, n. 1, p. 171-191, jan.-abril 2018

\section{Introdução}

No texto Apontamentos de 1970-1971, Bakhtin (2003) afirma que "a forma de autoria depende do gênero do enunciado. Por sua vez, o gênero é determinado pelo objeto, pelo fim e pela situação do enunciado" (p. 389, grifos nosso). Considerando, pois, que os gêneros do discurso são formas típicas de enunciado produzidas por um sujeito falante num diálogo permanente com outras vozes sociais em dadas condições espaço-temporais, assumimos, na esteira do pensamento bakhtiniano, que tanto quanto o diálogo com o já-dito, o diálogo com o interlocutor a quem se dirige o enunciado é dimensão constitutiva da produção do dizer, e, por assim dizer, de construção da autoria: "sem levar em conta a relação do falante com o outro e seus enunciados (presentes e antecipáveis), é impossivel compreender o gênero ou estilo do discurso. [...]." (BAKHTIN, 2003. p. 304, grifos nosso).

Podemos perceber, ademais, que, no pensamento de Bakhtin, o interlocutor, como respondente ativo que é quem assume diferentes matizes e posições sociais no intercâmbio comunicativo, está sempre se posicionando axiologicamente, expressando valores, esteja ele presente fisicamente ou não na cena enunciativa. E, nesse sentido, ele [o interlocutor] desempenha papel essencial nas escolhas estilísticas do sujeito que fala/escreve, participando ativamente da construção do dizer, da autoria. É, portanto, partindo desse entendimento que o presente trabalho ${ }^{1}$ examina a construção da autoria na escrita científica, objetivando identificar e analisar formas de dialogismo interlocutivo como marcas de construção da voz autoral do sujeito pesquisador na escrita de artigos científicos. Dado o nosso interesse pela escrita científica de jovens pesquisadores ${ }^{2}$, como expresso em nossa tese de doutorado já referida anteriormente, o trabalho aqui recortado está centrado

1 Este trabalho apresenta um recorte, com modificações e acréscimos, de um dos capítulos de análise da tese de doutorado Dialogismo e construção da voz autoral na escrita do texto científico de jovens pesquisadores (BESSA, 2016a).

2 Nosso trabalho assume, com base em Delcambre (2013), que o artigo científico do estudante de mestrado se trata de escrita de pesquisa em formação, por compreender que é uma experiência de aprendizado e de formação desse estudante para $\circ$ universo da pesquisa e da publicação científica. 
Linha D'Água (Online), São Paulo, v. 31, n. 1, p. 171-191, jan.-abril 2018

na investigação da escrita científica produzida no contexto acadêmico-científico brasileiro, focalizando o contexto da pós-graduação da área de Letras/Linguística ${ }^{3}$.

Considerando que, no pensamento do Círculo de Bakhtin, a autoria é tanto um tema aberto quanto uma questão instigante e provocadora, sujeita a múltiplas leituras, compreensões e “aplicações”, cujo reflexo é uma inegável contribuição que se soma aos debates sobre o tema, especialmente aqueles desenvolvidos em solo brasileiro, entendemos ser relevante lançarmos um olhar sobre essa questão focalizando a dimensão do dialogismo interlocutivo. Nossa empreitada se justifica com base no entendimento de que essa dimensão é ainda pouco explorada em pesquisas de nossa área que têm investigado a autoria, inclusive entre aquelas desenvolvidas por estudiosos que assumem a perspectiva dos estudos bakhtinianos ${ }^{4}$, sobretudo quando se trata de examiná-la em gêneros do discurso da esfera científica. Justifica-se, além disso, como possibilidade de aprofundamento de nossos estudos e de nossas reflexões sobre produção do conhecimento, escrita científica e ensino do texto acadêmico-científico, temáticas sobre as quais temos nos dedicado já há algum tempo (BESSA, 2017, 2016a, 2016b, 2014; BESSA, BERNARDINO, NASCIMENTO, 2012).

É necessário prestarmos alguns esclarecimentos. $\mathrm{O}$ primeiro diz respeito à ausência de uma seção específica para apresentação dos fundamentos teóricos que encoram o trabalho de análise realizado. O leitor é, pois, convidado a se reportar aos pressupostos teóricos que balizam a abordagem dialógica da linguagem do Círculo de Bakhtin (BAKHTIN, 2003, 2010a, 2010b, 2010c; MEDVIÉDEV, 2012; VOLOCHÍNOV, 2013), e se constituem como ancoragem teórica central de nosso trabalho. Como, em um estudo dessa natureza, não poderíamos deixar de nos reportarmos também às leituras de autores que discutem a escrita científica, em especial em perspectivas retórica, enunciativa e discursiva, salientamos, ao nosso leitor, que optamos por explicitar as posições, concepções e categorias analíticas desses autores, com as quais dialogamos aqui, ao longo da análise.

3 Este trabalho se filia a estudos que assumem a escrita científica em suas especificidades disciplinares como concebem Hyland (2004) e Bazerman (2014).

4 Quanto aos trabalhos sobre autoria numa perspectiva dos estudos bakhtinianos, mas que não estão voltados especificamente à exploração da dimensão do dialogismo interlocutivo, podemos citar, por exemplo, os textos de Brait (2010), Silva e Rodrigues (2009) e Francelino (2011). 
Linha D'Água (Online), São Paulo, v. 31, n. 1, p. 171-191, jan.-abril 2018

Um segundo esclarecimento está relacionado à explicitação, ainda que de forma sintética, da compreensão de autoria assumida no presente trabalho. Em sintonia com a perspectiva dos estudos bakhtinianos, concebemos a autoria como a expressão de uma experiência discursiva individual do sujeito falante que se constrói num permanente diálogo com os dizeres do(s) outro(s) em dadas condições sócio-históricas. Como esse direcionamento faz pensar que a construção autoral se dá no diálogo com os dizeres do(s) outro(s), tanto na dimensão de um já-dito quanto na dimensão da resposta antecipada do interlocutor, é preciso ressaltar que tomar apenas a dimensão interlocutiva para exame, conforme nos propomos aqui, não significa dizer que a dimensão do diálogo com o já-dito não esteja operante na maneira como o sujeito pesquisador constrói a sua voz autoral. Apenas por uma opção metodológica, essas duas dimensões podem ser separadas para estudo, afinal, em seu funcionamento real e concreto, elas interagem e precisam ser consideradas (ou pelo menos reconhecidas) pelo analista que assume, em seus trabalhos, a perspectiva dos estudos bakhtinianos.

O terceiro e último esclarecimento refere-se ao direcionamento metodológico da pesquisa. Os dados analisados fazem parte de uma pesquisa de doutorado em que investigamos manifestações do dialogismo e a construção da autoria em artigos científicos de estudantes de mestrado (compreendidos como jovens pesquisadores) sob a perspectiva dos estudos bakhtinianos. Em conformidade com uma epistemologia da pesquisa em ciências humanas, como depreendida do pensamento bakhthiniano, nosso olhar sobre o corpus, constituído de 10 artigos científicos coletados em anais de um dos eventos da Associação Brasileira de Linguística (ABRALIN), orientado pelo enfoque interpretativo e pela abordagem qualitativa da pesquisa.

\section{Manifestações do dialogismo interlocutivo na construção autoral em artigos científicos}

Os diferentes gêneros do discurso da esfera acadêmico-científica implicam pensar em diferentes formas e graus de influência do interlocutor sobre o dizer do sujeito produtor, conforme sejam as condições de produção, circulação e recepção desses gêneros. A propósito do texto de pesquisa, Amorim (2002, 2009), por exemplo, 
Linha D'Água (Online), São Paulo, v. 31, n. 1, p. 171-191, jan.-abril 2018

suscita, além de um interlocutor suposto/presumido, que corresponde a essa instância que é interior ao enunciado, um interlocutor real, que seria aquele que efetivamente lê o texto.

Sem negar que exista efetivamente a instância de um interlocutor real, como propõe Amorim $(2002,2009)$, que pode atuar efetivamente sobre a produção do artigo científico, concentramo-nos em focalizar marcas que indicam a presença do interlocutor presumido na constituição do dizer do jovem pesquisador. $\mathrm{O}$ interlocutor presumido se apresenta, utilizando-nos de termos de Bakhtin/Volochínov (2010), como um auditório social estabelecido/determinado, na atmosfera do qual se constrói certas motivações, julgamentos, apreciações e se produz o dizer. Sendo assim, para os propósitos da análise que empreendemos aqui, estamos considerando como interlocutor presumido, sem descartar outros, os pares, colegas pesquisadores que fazem parte da comunidade acadêmico-científica, formada principalmente por linguistas, considerando-se que os textos foram recortados exatamente dos anais de um dos eventos da ABRALIN, a mais importante entidade de pesquisadores da área no Brasil.

Nesse exercício de examinar marcas que indiciam a presença do interlocutor sobre o dizer do produtor/pesquisador, consideramos, na análise de nosso corpus, alguns mecanismos que estabelecem explicitamente que o produtor reconhece a presença e engajamento do interlocutor na construção de sentidos no texto científico, conforme concebidos por Hyland $(2001,2005)^{5}$. Destacamos, contudo, que a presente análise não se prende apenas aos mecanismos apontados por Hyland (2001, 2005), ainda que os consideremos como referência aqui. Queremos destacar também que não pretendemos, de maneira alguma, esgotar a multiplicidade de marcas que indiciam a presença e a influência do interlocutor no dizer do produtor nos textos analisados, mas basicamente apresentar aquelas que se mostraram de forma mais evidente ao nosso olhar responsivo sobre o corpus. Passemos, então, ao exame dessas marcas:

5 Cabe anotar que, ao propor esses mecanismos que assinalam engajamento do leitor na produção do texto científico, Hyland (2005) explicita textualmente apoiar-se na noção de dialogismo bakhtiniana. 
Linha D'Água (Online), São Paulo, v. 31, n. 1, p. 171-191, jan.-abril 2018

a) marcas de primeira pessoa reveladas no emprego de pronomes pessoais, desinências verbais e pronomes possessivos

$\mathrm{O}$ uso de pronomes pessoais, de desinências verbais e pronomes possessivos são, seguindo o estudo de Savio (2010), alguns dos principais índices que podemos utilizar para identificar as marcas de primeira pessoa que sinalizam a subjetividade do enunciador na produção discursiva. Citando alguns estudos sobre formas de caracterizar o sujeito da enunciação, a autora aponta que as marcas de primeira pessoa revelam diferentes funções discursivas. Dentre aquelas que se prestam a marcar a relação de influência do interlocutor sobre o produtor do texto se encontram, por exemplo, os casos em que o produtor, para assegurar a compreensão do seu dizer, guia e/ou chama a atenção do interlocutor para determinada informação ou aspecto do texto que ele considera relevante pontuar, como podemos verificar no excerto seguinte:

(1) O nosso trabalho tem como foco no gênero resenha acadêmico que assim como outro gênero, está ligado às práticas sociais discursivas realizadas pelos estudantes, a resenha se organiza partindo de atividades sociais como eventos, seminários, leituras e discussões e analisa uma determinada temática, Istoé, discute um determinado tema.

Trataremos aqui, especificamente da resenha acadêmica, exigida por professores universitários. Para diferenciar melhor a resenha acadêmica das outras resenhas, precisaremos compreender o que é esse gênero resenha, vejamos o que diz Medei$\operatorname{ros}\left(2000\right.$, p.137): [...] (AC07, p. 963) ${ }^{6}$.

6 Para assegurar a preservação da identidade dos autores dos textos coletados em nossa pesquisa, os artigos científicos foram codificados observando-se a seguinte identificação: AC01, ACO2, ACO3 e assim por diante, em que AC corresponde a Artigo Científico e os numerais cardinais $01,02,03$... correspondem a ordem numérica, estabelecida aleatoriamente, dos textos em nosso corpus. Ao longo das análises, procuramos nos referir aos autores dos artigos como produtores, para evitar qualquer conflito com a designação das vozes que eles citam em seus textos, as quais são referidas como autores, estudiosos, teóricos. Acompanhando a identificação do artigo, encontra-se ainda a indicação da(s) página(s) da qual foi recortado o excerto. Assim, ACO4, p. 4309 indica que o fragmento em análise se trata do artigo científico do produtor 04 e foi recortado da página 4309 do referido artigo. Além disso, os destaques 
Linha D'Água (Online), São Paulo, v. 31, n. 1, p. 171-191, jan.-abril 2018

No excerto acima, temos quatro ocorrências de marcas de primeira pessoa, as quais apontam para diferentes aspectos da relação de influência do interlocutor sobre o dizer do produtor do texto. Enquanto o uso da forma verbal precisaremos compreender, que, nesse contexto, aponta para um aspecto relevante (e necessário) que o produtor considera que seu interlocutor deva observar, pode ser caracterizado como um modalizador (ver também o tópico a seguir), o uso do possessivo na construção o nosso trabalho, bem como da forma verbal na construção trataremos aqui, sugerem que o produtor pretende demarcar, para seu interlocutor, uma opção feita no trabalho.

Esses dois últimos usos sinalizam uma preocupação por parte do produtor, ao antecipar possíveis objeções e/ou necessidade de esclarecimentos, de deixar claro para o seu interlocutor que tipo de resenha (resenha acadêmica) ele investiga em seu trabalho e sobre o tipo que ele discutirá, na sequência, naquela seção do texto. Fazendo isso, o produtor procura direcionar o interlocutor para acompanhar sua linha de argumentação, objetivando evitar que o interlocutor perceba, por exemplo, incoerências e/ou mesmo lacunas no trabalho.

Por sua vez, a forma verbal vejamos corresponde ao emprego do imperativo, por meio do qual o produtor convoca o interlocutor a diferenciar o tipo de resenha que ele estuda dos demais tipos existentes. O produtor faz isso convocando o interlocutor para observar a definição de resenha acadêmica apresentada por um autor/estudioso (Medeiros), ao qual ele (produtor) se reporta e de cujas posições compartilha. Ocorre que, com o uso do imperativo, o produtor visa a direcionar o interlocutor para uma determinada ação e/ou compreensão, conduzindo-o, assim, a observar uma definição importante para sustentação do argumento defendido, configurando, assim, o reconhecimento da dimensão dialógica na construção de sentidos na escrita científica.

em itálico, negrito e sublinhado que aparecem nos excertos são de nossa responsabilidade, dado o nosso propósito de realçar aspectos da análise.

BESSA, J. C. R. Dialogismo interlocutivo e construção da autoria em artigos científicos 
Linha D'Água (Online), São Paulo, v. 31, n. 1, p. 171-191, jan.-abril 2018

\section{b) modalizadores explícitos}

O uso de modalizadores no texto científico, como marca de um diálogo do produtor com seu interlocutor, já foi estudado por autores como Coracini (2007), Sionis (2002) e Hyland (2001). No trabalho de Coracini (2007), centrado no estudo da subjetividade no discurso científico, a autora classifica diferentes formas de modalização explícita, compreendidas como uma decorrência "da antecipação por parte do interlocutor de possíveis refutações (contra-argumentos, contraprovas) a asserções ou conclusões baseadas nos dados, na teoria e metodologia adotadas" (CORACINI, 2007, p. 131). Embora normalmente os modalizadores sejam usados por oposição a asserções neutras e generalizantes, é preciso considerar que as razões para fazer uso de modalizações na escrita científica são muito numerosas e muito sutis (SIONIS, 2002).

Haja vista a existência desses estudos e a compreensão de que o uso de modalizadores é constitutivo da subjetividade que atravessa o texto científico, podendo manifestar-se de diferentes formas, focalizamos aqui, sem pretensão exaustiva, apenas alguns casos - que consideramos mais relevantes - de modalização encontrados no nosso corpus, com o propósito de demonstrar como, por meio do uso desse recurso, o produtor constrói o seu dizer antecipando a (re)ação do seu interlocutor e/ou querendo orientar a compreensão deste para o modo como ele (produtor) interpreta um dado de sua pesquisa, como avalia suas hipóteses ou determinada concepção ou conceito da fundamentação teórica que desenvolve ou ainda como atenua suas conclusões, por exemplo.

Nos textos examinados, esse recurso se manifesta de diferentes formas e em diferentes seções dos artigos, englobando, por exemplo, o uso de advérbios (talvez; perfeitamente; profundamente; provavelmente; claramente; completamente; extremamente e exatamente), adjetivos (importante; fundamental; necessário; preocupante; relevante) de verbos (crer; acreditar; entende e poder), de tempos verbais (poderá; poderia e poderiamos), de glosas metaenunciativas (de certa forma; digamos; negociando com o já dito, reiteramos e Tomando por empréstimo as perguntas retóricas do autor), mas principalmente de locuções verbais (pode ser; parece ser; autoriza a sugerir; podemos dizer, pode representar; pode indicar; pode ser apontada; podemos inferir 
Linha D'Água (Online), São Paulo, v. 31, n. 1, p. 171-191, jan.-abril 2018

e podemos designar) que revelam uma preocupação do produtor, sobretudo com a necessidade de atenuar as afirmações/declarações que realiza ou as intepretações que vai construindo em seu texto, como observamos nos excertos que seguem:

(2) Constituímos o corpus com textos de dois gêneros em específico: relatório de estágio e monografia; o primeiro deles em função de as referências teóricas terem em sua tessitura "apenas um papel de apoio para a reflexão e a análise" (BOCH; GROSSMANN, 2002, p. 99); o segundo, em função de se constituir como trabalho de conclusão de curso e, como tal, exigir que o aluno demonstre um dominio aprofundado das teorias relacionadas ao objeto de análise, já que a dimensão teórica é de fundamental importância, o que pode indicar as especifidades no uso dos modos de discurso citado em tais gêneros. (AC08, p. 2069-2070).

(3) Poderíamos chamar de "estilo" essas escolhas e modos de elaboração textual de cada jovem autor? Entendemos que sim. E, para tal afirmação, buscamos apoio no argumento oferecido por Brait (2006, p. 54): [...] (AC01, p. 65).

(4) Talvez o conceito de texto e, por consequência, o de intertexto tenham de ser reavaliados permitindo que outros elementos semióticos sejam contemplados ao conceito. (AC03, p. 4356).

(5) A análise dos recados/bilhetes encontrados em atividades escolares permitiu investigar se há algum indicio de escrita digital em suportes diferentes do computador. Hipótese confirmada, uma vez que já aparece uma escrita que pode ser associada a construções da escrita digital em suportes como o papel. (AC04, p. 4315)

(6) Cremos que esse texto foi também um exercício de utilização de vozes alheias para uma elaboração de uma nova voz, de um novo dito, foi uma maneira de relacionar as partes para construir esse todo - o texto -, e esse mesmo texto continuará recebendo todos os acentos do meio social no qual circula ou circulará. (AC09, p. 1953) 
Linha D'Água (Online), São Paulo, v. 31, n. 1, p. 171-191, jan.-abril 2018

Nos cinco excertos acima, os termos destacados em negrito - o que pode indicar, poderíamos, talvez, pode ser e cremos - ilustram o uso de modalizadores em diferentes seções dos artigos científicos (exceto na seção de metodologia), o que mostra que esse recurso se presta ao propósito do produtor de modalizar o seu dizer com orientações expressivas distintas, seja para justificar o corpus da pesquisa, como em (02); seja para definir ou questionar um conceito, como em (03) e (04), respectivamente; seja para interpretar/analisar dados, como em (05); seja, por fim, para ponderar as conclusões a propósito do trabalho realizado, como em (06). Em todos esses casos, vemos um trabalho do produtor sobre o dizer, no sentido de relativizar o conteúdo de suas asserções/declarações, de maneira a orientar e direcionar a compreensão do interlocutor, e, consequentemente, tentar ganhar a aceitação de seus argumentos e posições.

Ainda que seja verdadeiro que os jovens pesquisadores revelem dificuldades com o uso de modalizações, como aponta Boch (2013) a propósito de textos de doutorandos, a relativa regularidade no uso de modalizadores nos textos de nosso corpus mostra como os jovens pesquisadores têm incorporado (e relativamente bem, ainda que seu uso devesse ser mais encorajado, com a devida coerência e de modo consciente, sobretudo quando da construção de intepretações e compreensões dos dados) essa característica essencial da escrita científica, posto que têm buscado evitar a manifestação de afirmações e de posições expressas de forma categórica, o que é salutar em trabalhos que se fundam na compreensão como característica central da construção do conhecimento. Isso se mostra mais significativo sobretudo quando consideramos que estudantes de graduação generalizam excessivamente quando realizam o procedimento de reformular o dizer do outro, como anotam Pollet e Piette (2002), mas não só nessas circunstâncias, já que, conforme podemos deduzir de estudo de Delcambre e Reuter (2002), os textos de estudantes universitários são tendencialmente esvaziados de algumas categorias de marcadores linguísticos de dúvida e de modalização. 
Linha D'Água (Online), São Paulo, v. 31, n. 1, p. 171-191, jan.-abril 2018

c) comentários que interrompem ofluxo do dizer

Os comentários que interrompem o fluxo do dizer nos textos científicos examinados, como forma de manifestação do dialogismo interlocutivo, podem aparecer de três modos, entre travessões, entre parênteses e em notas de rodapé, e cumprem variadas funções discursivas no projeto de dizer do jovem pesquisador, mas, em geral, estão atreladas ao propósito do produtor de ir controlando os sentidos e direcionando a compreensão do interlocutor para determinada linha argumentativa adotada ou para as posições que aquele assume. Observemos os excertos abaixo:

(7) Orienta este trabalho a tese - amplamente aceita entre os estudiosos da linguagem situados numa perspectiva enunciativo-discursiva-de que a referência ao discurso do outro é um fenômeno recorrente, natural e característico dos textos de um modo geral. (AC08, p. 2069).

(8) Vale considerar, ainda, que não estamos tratando exclusivamente do autor referido por Foucault (1992), aquele que é reconbecido pela obra a ele vinculada ou pela fundação de uma discursividade (apesar de referenciarmos o autor na construção de nosso argumento sobre uma das condições de autoria apresentadas neste texto). (AC01, p. 63)

(9) Este trabalho é um recorte de nossa dissertação de Mestrado (LIMA-NETO 2009), que justifica o interesse pelo scrap porque ele é constituído por diversos padrões genéricos ${ }^{7}$, muitas vezes amalgamados entre si, como também permite a mescla de diversas semioses, ocasionando um novo modo de enunciar, o digital (XAVIER, 2002), traço característico da hipertextualidade que lhe é intrínseca (LOBO-SOUSA, 2009).

7 Chamamos "padrão genérico" ou "padrão de genericidade" os traços estilísticos, composicionais e conteudísticos prototípicos de um determinado gênero discursivo. (ACO1, p. 43504351)

BESSA, J. C. R. Dialogismo interlocutivo e construção da autoria em artigos científicos 
Linha D'Água (Online), São Paulo, v. 31, n. 1, p. 171-191, jan.-abril 2018

Como podemos verificar, os três excertos acima se caracterizam pelo acréscimo, no fluxo do texto, de uma informação, entenda-se um comentário, conforme destacado em negrito, que, em (07), aparece entre travessões; em (08), entre parênteses; e, em (09), em nota de rodapé. Embora expressos, formalmente, de modos diferentes, os comentários revelam um propósito comum de seus produtores de tentarem controlar os sentidos do dizer, na medida em que procuram ponderar e antecipa possíveis objeções de seus interlocutores. Em (07), o produtor revela uma preocupação de demarcar/delimitar para o seu leitor a perspectiva teórica que postula a tese de que a referência ao discurso do outro é um fenômeno recorrente, natural e característico dos textos de um modo geral, na qual ele se fundamenta em seu trabalho. Já em (08), o produtor antecipa uma possível pergunta (não expressa textualmente) de seu interlocutor e esclarece porque, não tratando especificamente de autoria nos termos de Foucault já que recorre a uma certa concepção de autor expressa no pensamento bakhtiniano - se apoia na visão foucaultiana para focalizar as condições de autoria. Em (09), por sua vez, o produtor entende a necessidade de delimitar para o seu interlocutor sob que viés concebe a ideia de padrão genérico que constitui o scrap, objeto que investiga, remetendo o interlocutor para uma definição em nota de rodapé.

Nesses casos, os travessões, os parênteses e as notas de rodapé constituem um traço que evidencia que o produtor constrói seu dizer no horizonte das apreensões responsivas de seu interlocutor, procurando fazer com que esse veja e compreenda de uma perspectiva e não de outra, tentando, portanto, direcionar a construção dos sentidos.

\section{d) elementos contextualizadores de discurso citado ${ }^{8}$}

Estamos concebendo os elementos contextualizadores de discurso citado como expressão do dialogismo interlocutivo, por entendermos que, quando em um contexto linguístico de introdução do discurso citado, o produtor acrescenta informações que

8 A designação dessa marca toma como parâmetro a ideia de contextualização do discurso representado como postulada por Fairclough (2001), em seu estudo sobre a intertextualidade, no livro Discurso e Mudança Social. 
Linha D'Água (Online), São Paulo, v. 31, n. 1, p. 171-191, jan.-abril 2018

contextualizam o dizer, ele está antecipando possíveis objeções de seu interlocutor e, ao mesmo tempo, buscando assegurar/conferir mais credibilidade ao seu dizer.

É possível verificarmos, em nosso corpus, que as informações que se enquadram como elementos contextualizadores de discurso citado são as mais diversas, mas aquelas que precisamente indicam uma influência mais nítida do interlocutor sobre o dizer do produtor do texto compreendem o caso da delimitação de perspectiva(s) teórica(s) de autor(es) citado(s). Tal marca foi observada em passagens conforme se encontram no excerto que segue:

(10) Foucault (1992), Souza (2006) e Machado (2000), a partir de perspectivas distintas, insistem nesta questão primordial relativamente à autoria na produção de textos escritos: a exposição ao outro, implicita no ato de escrever. Com denominações variadas, todos se referem à exposição ao outro. (AC01, p. 67)

Neste excerto, compreendemos que, ao introduzir a posição de mais de um autor/estudioso (no caso Foucault (1992), Souza (2006) e Machado (2000)), sobre uma mesma questão, a questão da exposição ao outro como condição da autoria na produção de textos escritos, o produtor do AC01 resolve explicitar, de antemão, para o seu interlocutor, sua posição por focalizar a questão com base em autores que enunciam a partir de perspectivas distintas. Entendemos que aí o produtor, como que supondo uma possível provocação/questionamento de seu interlocutor em relação ao fato de ele evocar a discussão sobre uma concepção teórica sob a perspectiva de autores situados em lugares teóricos diferentes, adota a estratégia de contextualizar o dizer que cita.

Ao proceder assim, o produtor do AC01 não só constrói o seu dizer no horizonte de uma resposta antecipada de seu interlocutor, como também confere mais credibilidade ao seu dizer, na medida em que, além de convocar três diferentes posições para tratar de uma mesma questão, observa relações entre elas, demonstrando, dessa forma, conhecer as especificidades que caracterizam cada uma dessas posições.

e) expressões que manifestam juizos de valor 
Linha D'Água (Online), São Paulo, v. 31, n. 1, p. 171-191, jan.-abril 2018

Embora as expressões que manifestam juízos de valor sejam também, conforme estudo de Coracini (2007), uma forma de modalização do dizer, seguimos aqui a ideia de Hyland (2005), concebendo-as separadamente, considerando que elas têm uma finalidade mais específica, que é assinalar um julgamento de necessidade e de relevância por parte do produtor em relação a determinado aspecto do trabalho. $\mathrm{O}$ uso dessas expressões se dá sob a forma de construções linguísticas como é importante que, vale ressaltar que, é necessário reconhecer, não podemos deixar de ressaltar que, cumpre destacar que, convém destacar que, cabe destacar que, cabe destacarmos, cabe ressaltar, convém lembrar, convém relatar, o que vale apena ressaltar é, entre outras, que assinalam que o produtor visa a chamar a atenção de seu interlocutor para um dado aspecto do trabalho que ele quer realçar, conforme podemos ver nos exemplos abaixo:

(11) Cabe ressaltar ainda o jogo discursivo feito pela alusão a Napoleão Bonaparte, lider da Revolução Francesa e Hugo Chávez, presidente da Venezuela, em expressões adjetivadas pelo termo "cordial". (AC02, 2232)

(12) É importante destacar que numa mesma palavra pode haver mais de um traço da linguagem digital, ou nenhum deles, existindo uma liberdade para o usuário da lingua, privilegiando apenas a comunicação. (AC04, p. 4312)

Nos dois exemplos acima, podemos observar que o uso das construções linguísticas Cabe ressaltar e é importante destacar que são caracterizadas por uso de expressões injuntivas (cabe, é importante ... que) e verbos que manifestam um juízo de valor (ressaltar, destacar) que cumprem a finalidade de realçar a relevância do conteúdo do dizer, de modo que, por meio dessas expressões, o produtor do texto objetiva direcionar a atenção do interlocutor. Aqui, o produtor vai construindo o seu dizer pautando suas escolhas linguísticas no horizonte daquilo que ele julga ser relevante que seu interlocutor deva considerar na leitura do texto. 
Linha D'Água (Online), São Paulo, v. 31, n. 1, p. 171-191, jan.-abril 2018

f) referências ao conhecimento compartilhado

Seguindo Hyland (2005), entendemos que é possível demarcar a relação interlocutiva na escrita científica observando marcas que denotam que o produtor do texto compartilha conhecimento com seu interlocutor. Nesse caso, o produtor convida o leitor a reconhecer algo como familiar ou já aceito. Assim, ele pressupõe e antecipa que determinada informação é compartilhada pelo seu interlocutor, que passa a participar do dizer do produtor e contribuir com a construção do(s) seu(s) argumento(s). Os casos mais comuns dessa forma de relação interlocutiva são aqueles caracterizados pelo uso de advérbios tais como obviamente, naturalmente e claro. Consideremos um desses casos no excerto a seguir:

(15) Bakhtin, obviamente, nada disse sobre a comunicação das modernas midias digitais, mas suas formulações convergem e muito contribuem para a o entendimento delas. Assim, a pesquisa é consonante com a teoria bakhtiniana da transmutação dos gêneros, que é uma tendência, principalmente diante dos avanços digitais e das necessidades comunicativas. (AC04, p. 4315)

Nesse exemplo, o uso do advérbio obviamente assinala que o produtor de AC04 constrói o dizer antecipando que seu interlocutor compartilha de sua linha argumentativa. Não se trata aqui de pensar apenas que o produtor se utiliza de um modalizador para assegurar certeza da asserção que faz. Trata-se de considerar, especialmente, que o produtor parte da convicção de que seu interlocutor tem conhecimento sobre o que aquele declara e ainda que esse compartilha e corrobora a compreensão que aquele constrói. No exemplo, o produtor demonstra acreditar que os leitores de Bakbtin têm convicção de que este nada disse sobre a comunicação das modernas midias digitais, o que aponta, portanto, que ele (produtor) pressupõe que essa seja uma informação familiar para os interlocutores. Desse modo, o interlocutor age sobre o dizer do produtor, influenciando e determinando suas escolhas; em outras palavras, ele age demarcando seu lugar na construção do projeto de dizer do produtor do texto. 
Linha D'Água (Online), São Paulo, v. 31, n. 1, p. 171-191, jan.-abril 2018

g) expressões que denotam explicitamente um diálogo aberto

Ainda que, de uma perspectiva bakhtiniana, seja lugar-comum dizer que todo enunciado se constrói antecipando uma resposta ativa do interlocutor, há casos em que a disposição do produtor para o diálogo se deixa mostrar, formalmente, de maneira mais marcada, mais evidente. Isso ocorre, por exemplo, quando o produtor faz uso de expressões que denotam explicitamente uma abertura ao diálogo, expressões por meio das quais assinala, linguisticamente, que os sentidos que ele constrói não encerram as possibilidades de compreensão do objeto tratado. Vejamos os excertos abaixo:

(16) Nessas considerações, apresentamos resultados inacabados, os quais suscitam pesquisas futuras, visando assim, contribuir para a construção de novos saberes e consequentemente, contribuir para o crescimento e acadêmico daqueles que compóem esse o universo: professor e aluno. (AC06, p. 972-973)

(17) Cremos que esse texto foi também um exercicio de utilização de vozes alheias para uma elaboração de uma nova voz, de um novo dito, foi uma maneira de relacionar as partes para construir esse todo -o texto -, e esse mesmo texto continuará recebendo todos os acentos do meio social no qual circula ou circulará. (AC09, p. 1953).

Em (16) e (17), as construções linguísticas apresentamos resultados inconclusos e esse texto continuará recebendo todos os acentos do meio social... evidenciam que seus respectivos produtores assumem que a compreensão construída com os resultados do trabalho, o texto constitui um diálogo aberto com o seu interlocutor. Mais que uma mera estratégia de relativização do dizer, o uso dessas expressões sinaliza que o produtor provoca o outro a entrar no debate, a ser mais um sujeito, na cadeia complexa do dizer, a construir sentidos sobre o objeto de que trata.

Uma indicação mais clara da influência do interlocutor sobre o dizer do produtor pode ser observada quando consideramos o aspecto das concepções teóricas compartilhadas por cada produtor. Como os dois trabalhos compartilham centralmente de posições teóricas do pensamento bakhtiniano, acreditamos que o uso 
Linha D'Água (Online), São Paulo, v. 31, n. 1, p. 171-191, jan.-abril 2018

dessas expressões indique a preocupação do produtor de construir um dizer que reflita as expectativas de outros leitores do pensamento bakhtiniano. Ou seja, o produtor assume a compreensão de que deve moldar seu dizer respeitando o modo bakhtiniano de construção do conhecimento, fundado, por exemplo, na abertura ao diálogo, bem como no não fechamento dos sentidos, porque entende que o seu interlocutor espera isso dele. Assim, o produtor marca aí a participação ativa do interlocutor em seu dizer.

Uma vez expostas as marcas que assinalam explicitamente o encontro com o outro na destinação exploradas no corpus de nossa pesquisa, pudemos constatar que essas marcas nos permitem demarcar um interlocutor que age ativamente sobre o dizer do produtor de variadas maneiras e com graus de interferências com diferentes nuanças, as quais podem ser consideradas bastante produtivas do ponto de vista das possibilidades expressivas do dizer do pesquisador, o que confirma, parafraseando Volochínov (2013), que a dimensão da orientação social do enunciado tem um papel essencial e decisivo na construção da estrutura estilística, revelado no tom do dizer, nas escolhas e na disposição das palavras, dos textos analisados.

É preciso ter claro, entretanto, que não está no horizonte do produtor um interlocutor precisamente definido, mais específico e particular, mas uma espécie de grupo social, mais amplo, sua comunidade disciplinar, em relação a qual ele pode construir imagens, antecipar expectativas, compreensões e possíveis problemas de compreensão em relação ao dito. É, portanto, no horizonte dessas apreciações e réplicas antecipadas que o produtor vai organizando e orquestrando o seu dizer, na tessitura do artigo científico, e constituindo, desse modo, uma autoria, que, articulada necessariamente e constitutivamente com um já-dito, se mostra fortemente marcada pela influência de um interlocutor presumido.

\section{Conclusão}

Como parte de nossos interesses de investigação sobre a escrita do texto acadêmico-científico e em particular sobre a construção da autoria nessa escrita, objetivamos, no recorte que configura o presente trabalho, identificar e analisar formas 
Linha D'Água (Online), São Paulo, v. 31, n. 1, p. 171-191, jan.-abril 2018

de dialogismo interlocutivo como marcas de construção da voz autoral do sujeito pesquisador na escrita do artigo científico.

Compreendendo que, quando falamos ou escrevemos, deixamos, em nossos dizeres, marcas diversas da influência do outro a quem endereçamos o dizer, procuramos identificar e interpretar marcas que revelassem indícios da influência do interlocutor na construção do dizer do produtor dos artigos científicos examinados. Reportando-nos sobretudo a estudos de Hyland (2001, 2005), que apontam alguns mecanismos que revelam que o produtor reconhece a presença do leitor e o seu engajamento na produção de sentidos no texto científico, mas não nos limitando a tal estudo, pudemos identificar uma variedade de marcas que indiciam os intensos diálogos que o produtor trava com seu interlocutor na construção do dizer.

O exame dessas marcas nos permitiu demarcar um interlocutor que age sobre o dizer do produtor de diferentes maneiras e com graus e nuanças de interferências variadas, as quais, via de regra, se mostraram bastante enriquecedoras do ponto de vista das possibilidades expressivas na construção da voz autoral do pesquisador. Na medida em que pressupõe e antecipa, com maior ou menor intensidade, aspectos como dificuldades de compreensão e possíveis dúvidas e questionamentos em relação ao conteúdo do dizer por parte do interlocutor presumido, o produtor vai, portanto, orientando e orquestrando o seu dizer, na tessitura do artigo científico, no horizonte de reações, expectativas, julgamentos e apreciações desse seu interlocutor, configurando, assim, uma construção autoral que se realiza de maneira fortemente marcada pela dimensão do dialogismo interlocutivo.

\section{Referências}

AMORIM, M. Freud e a escrita de pesquisa - uma leitura bakhtiniana. Eutomia, v. 2, p. 01-14, 2009.

.Vozes e silêncio no texto de pesquisa em ciências humanas. Cadernos de Pesquisa, n. 116, p. 7-19, jul. 2002.

BAKHTIN, M. Problemas da poética de Dostoiérski. Trad. do russo de Paulo Bezerra. 5. ed. Rio de Janeiro: Forense Universitária, 2010a. 
Linha D'Água (Online), São Paulo, v. 31, n. 1, p. 171-191, jan.-abril 2018

BAKHTIN, M. Questões de literatura e de estética: a teoria do romance. Equipe de trad. do russo de Aurora Fornoni Bernardini, José Pereira Júnior, Augusto Góes Júnior, Helena Spryndis Nazário e Homero Freitas de Andrade. 6. ed. São Paulo: Hucitec, 2010b.

BAKHTIN, M. (VOLOCHÍNOV). Marxismo e Filosofia da linguagem. Trad. do francês de Michel Lahud e Yara Frateschi Vieira. 14. ed. São Paulo: Hucitec, 2010c.

BAKHTIN, M. Estética da criação verbal. Trad.do russo de Paulo Bezerra. 4. ed. São Paulo: Martins Fontes, 2003.

BAZERMAN, C. El descubrimento de la escritura acadêmica. Traducción de Natalia Ávila Reye. In: NAVARRO, F. (Coord.). Manual de escritura para carreras de humanidades. Ciudad Autónoma de Buenos Aires: Editorial de la Facultad de Filosofía y Letras Universidad de Buenos Aires, 2014, p. 11-16.

BESSA, J. C. R. Formas de presença da palavra alheia em artigos científicos de jovens pesquisadores. Revista Trama, v. 13, p. 143-178, 2017.

BESSA, J. C. R. Dialogismo e construção da voz autoral na escrita do texto cientifico de jovens pesquisadores. 2016, 385 f. Tese (Doutorado em Linguística e Língua Portuguesa) - Universidade Estadual Paulista "Júlio de Mesquita Filho", Faculdade de Ciências e Letras (Campus Araraquara), 2016a.

BESSA, J. C. R. O discurso citado na macroestrutura textual de artigos científicos de jovens pesquisadores. Ilha do Desterro, v. 69, p. 45-62, 2016b.

BESSA, J. C. R. Por uma cultura de ética e de integridade do pesquisador em formação inicial. Revista Espaço Acadêmico, v. 14, p. 114-121, 2014.

BESSA, J. C. R.; BERNARDINO, R. A. S.; NASCIMENTO, I. A. de A. A citação na escrita acadêmico-científica de estudantes universitários: da paráfrase ao plágio. Encontros de Vista, v. 9, p. 1-9, 2012.

BRAIT, B. Vozes entre as dobras da autoria. Revista da ABRALIN, v. 15, p. 53-82, 2016.

BRAIT, B. Dialogismo, estilo e práticas acadêmicas. In: PERNAMBUCO, J.; FIGUEIREDO, M. F.; SALVIATO-SILVA, A. C. (Org.). Nas trilhas do texto. (Coleção Mestrado em Linguística, 5). Franca: Universidade de Franca, 2010, p. 14-33. 
Linha D'Água (Online), São Paulo, v. 31, n. 1, p. 171-191, jan.-abril 2018

$\mathrm{BOCH}, \mathrm{F}$. Former les doctorants à l'écriture de la thèse en exploitant les études descriptives de l'écrit scientifique. Linguagem em (Dis)curso, Tubarão, SC, v. 13, n. 3, p. 543-568, set./dez. 2013.

CORACINI, M. J. Um fazer persuasivo: o discurso subjetivo da Ciência. 2. ed. Campinas: Pontes, 2007.

DELCAMBRE, I. Le mémoire de master: ruptures et continuités. Points de vue des enseignants, points de vue des étudiants. Linguagem em (Dis)curso, Tubarão, SC, v. 13, n. 3, p. 569-612, set./dez. 2013.

DELCAMBRE, I; REUTER, Y. Le rapport a l'ecriture d'etudiants em licence et maitrise: premiere approche. Spirale, n. 29, p. 7-27, 2002.

FAIRCLOUGH, N. Discurso e mudança social. Coordenação de tradução, revisão técnica e prefácio de Izabel Magalhães. Brasília: Editora Universidade de Brasília, 2001.

FRANCELINO, P. de F. Enunciação, dialogismo e autoria em enunciados midiáticos verbovisuais. Revista Moara, n.36, p.104-114, jul./dez., 2011.

HYLAND, K. Bringing in the reader: addressee features in academic writing. Written Communication, 18(4), p. 549-574, 2001.

HYLAND, K. Disciplinary discourses: social interactions in academic writing. Michigan: The University of Michigan Press, 2004.

HYLAND, K. Stance and engagement: a modelo of interaction in academic discourse. Discourse studies, 7(2), 173-192, 2005.

MEDVIÉDEV, P. N. O método formal nos estudos literários: introdução crítica a uma poética sociológica. Tradução de Ekaterina Vólkova Américo e Sheila Camargo Grillo. São Paulo: Contexto, 2012.

POLLET, M.; PIETTE, V. Citation, reformulation du discours d'autrui. Une clé pour enseigner l'écriture de recherche ? Spirale, n. 29, p. 165-179, 2002.

SAVIO, A. K. Las huellas del autor en el discurso académico: un estudio sobre tesis de psicoanalistas argentinos. Lenguaje, 38 (2), 563-590, 2010. 
Linha D'Água (Online), São Paulo, v. 31, n. 1, p. 171-191, jan.-abril 2018

SILVA, N. R. da; RODRIGUES, R. H. A autoria no gênero entrevista pingue-pongue. Revista Linguas e Letras. v. 10 n. 19, p. 333-363, 20 sem. 2009.

SIONIS, C. Quelques spécificités de la modalisation dans le discours scientifique. ASp, v. 35, n. 36, 49-59, 2002.

VOLOCHÍNOV, V. N. A construção da enunciação e outros ensaios. Organização, tradução e notas de João Wanderley Geraldi. São Carlos: Pedro \& João Editores, 2013.

Recebido: 30/09/2017.

Aprovado: 13/02/2018.

BESSA, J. C. R. Dialogismo interlocutivo e construção da autoria em artigos cientificos 